\title{
REQUIREMENT FOR COBALAMIN BY SALMONELLA ENTERICA SEROVARS TYPHIMURIUM, PULLORUM, GALLINARUM AND ENTERITIDIS DURING INFECTION IN CHICKENS
}

\author{
Jacqueline Boldrin de Paiva ${ }^{1}$, Rafael Antonio Casarin Penha Filho ${ }^{1}$, Angelo Berchieri Junior ${ }^{*}$, Manoel Victor Franco \\ $\operatorname{Lemos}^{2}$
}

\author{
${ }^{1}$ Departamento de Patologia Veterinária, Faculdade de Ciências Agrárias e Veterinárias, Universidade Estadual Paulista, \\ Jaboticabal, SP, Brasil; ${ }^{2}$ Departamento de Biologia, Faculdade de Ciências Agrárias e Veterinárias, Universidade Estadual \\ Paulista, Jaboticabal, SP, Brasil.
}

Submitted: June 07, 2010; Returned to authors for corrections: January 26, 2011; Approved: May 16, 2011.

\begin{abstract}
Salmonella enterica serovar Typhimurium synthesizes cobalamin (vitamin $\mathrm{B}_{12}$ ) only during anaerobiosis. Two percent of the $S$. Typhimurium genome is devoted to the synthesis and uptake of vitamin $\mathrm{B}_{12}$ and to $\mathrm{B}_{12-}$ dependent reactions. To understand the requirement for cobalamin synthesis better, we constructed mutants of Salmonella serovars Enteritidis and Pullorum that are double-defective in cobalamin biosynthesis $(\Delta \operatorname{cobS} \Delta \operatorname{cbi} A)$. We compared the virulence of these mutants to that of their respective wild type strains and found no impairment in their ability to cause disease in chickens. We then assessed $\mathrm{B}_{12}$ production in these mutants and their respective wild type strains, as well as in S. Typhimurium $\Delta$ cobS $\Delta$ cbiA, Salmonella Gallinarum $\Delta \operatorname{cobS} \Delta \operatorname{cbiA}$, and their respective wild type strains. None of the mutants was able to produce detectable $\mathrm{B}_{12}$. $\mathrm{B}_{12}$ was detectable in $S$. Enteritidis, $S$. Pullorum and $S$. Typhimurium wild type strains but not in $S$. Gallinarum. In conclusion, the production of vitamin $\mathrm{B}_{12}$ in vitro differed across the tested Salmonella serotypes and the deletion of the cbiA and cobS genes resulted in different levels of alteration in the host parasite interaction according to Salmonella serotype tested.
\end{abstract}

Key words: Salmonella, cobalamin, gene deletion, chickens.

\section{INTRODUCTION}

Cobalamin (vitamin $\mathrm{B}_{12}$ ) is a large, evolutionarily conserved cofactor and is one of the most structurally complex biomolecules described $\left(12,39\right.$, 40). Vitamin $B_{12}$ is derived from uroporphyrinogen III (Uro III), which is a common precursor in the synthesis of heme, siroheme, cobnamides, and chlorophylls, the latter playing a functional role functioning in photosynthetic organisms.

Salmonella enterica serovar Typhimurium synthesizes cobalamin de novo during anaerobiosis (20), and researchers have speculated that this is carried out by all Salmonella

\footnotetext{
*Corresponding Author. Mailing address: Department of Veterinary Pathology, School of Agronomic and Veterinary Sciences, UNESP - São Paulo State University, 14884-900, Jaboticabal, SP, Brazil..; E-mail: berchier@ fcav.unesp.br
} 
isolates $(24,32)$. Nearly $1 \%$ of the $S$. Typhimurium genome is devoted to the synthesis and uptake of cobalamin. An additional $1 \%$ is involved in metabolic pathways that require cobalamin (36). Only four vitamin $\mathrm{B}_{12}$-dependent reactions are known to exist in Salmonella Typhimurium. First, $\mathrm{B}_{12}$ is required by one methyltransferase, the product of the gene $m e t H$, which catalyzes the methylation of homocysteine to form methionine (31). Second, $\mathrm{B}_{12}$ is required for the cleavage of ethanolamine into acetaldehyde and ammonia, providing both a carbon and a nitrogen source $(34,35)$. Third, $B_{12}$ is involved in the formation of the nonessential hyper-modified $\mathrm{Q}$ base found in the anti-codon of tRNA ${ }^{\text {Asp,Asn,His,Tyr }}(15)$. Finally, the main use of $\mathrm{B}_{12}$ appears to be as a cofactor for propanediol dehydratase, the first enzyme in the propanediol degradation. This finding is based on evidence showing that the cob operon, which encodes the $B_{12}$ biosynthetic genes, is induced in response to propanediol and is co-regulated with the $p d u$ operon, which encodes genes that are required for propanediol degradation. This regulatory pattern suggests that propanediol might be a useful carbon and energy source under anaerobic conditions $(18,6)$. Interestingly, these $\mathrm{B}_{12}$-dependent reactions are not necessary for the laboratory cultivation of Salmonella in either aerobic or anaerobic conditions. This large genetic investment in the production and utilization of vitamin $B_{12}$ suggests that $\mathrm{B}_{12}$-dependent metabolism might be important during Salmonella infection. Therefore, vitamin $\mathrm{B}_{12}$ biosynthesis might be important under specific conditions, such as during Salmonella growth within its animal hosts. Furthermore, the selective pressure to maintain $B_{12}$ synthesis might vary with the lifestyle of the organism, as well as in the host-parasite relationship (36).

The genus Salmonella can be divided in two groups based on bacterial pathogenesis and infection biology. The first group includes the majority of the recognized serovars and infects a broad range of host species. Bacteria from this group colonize the gastrointestinal tracts of poultry, resulting in no clinical symptoms in chickens but causing gastroenteritis in humans.
The bacteria contaminate the infected animal carcasses during processing, thereby accessing the human food chain and leading to enteric fever, gastroenteritis, bacteremia and systemic infection. This group of bacteria includes the Salmonella enterica serovar Enteritidis in poultry. The second group includes a few serovars that produce systemic typhoidlike diseases in healthy, immunologically mature adult animals and derive from a limited range of host species. This second group includes the Salmonella enterica serovars Pullorum and Gallinarum, which are host-specific for poultry. Bacterial multiplication mainly takes place in the cells of the reticuloendothelial system (10). Although infection is typically introduced via the fecal-oral route, these Salmonella strains do not colonize the digestive tract. Salmonella Typhimurium is one of the leading causes of food poisoning in both humans and mice.

We recently demonstrated that the double mutant $S$. Gallinarum $\Delta \operatorname{cobS} \Delta c b i A$ is avirulent in chickens and that the mortality of chickens infected by $S$. Typhimurium $\Delta c o b S \Delta c b i A$ is reduced to half that induced by the wild type strain $(30,41)$.

In the present work, $S$. Enteritidis and $S$. Pullorum $\Delta c o b S \Delta c b i A$ mutants were generated. Their virulence was compared to the virulence of their respective wild type strains, and assays to detect cobalamin production in the wild type and mutant strains were performed. The $S$. Typhimurium $\Delta \operatorname{cobS} \Delta c b i A$ and $S$. Gallinarum $\Delta \operatorname{cobS} \Delta \operatorname{cbiA}$ strains were included in the latter assays.

\section{MATERIALS AND METHODS}

\section{Bacterial strains and culture media}

The designation and source of each bacterial strain used in this study are provided in Table 1. Cultures for transductions and inoculums were grown in $10 \mathrm{~mL}$ of Luria Bertani broth (LB) (Invitrogen $\left.N^{\circ} 12780-052\right)$ and incubated for 24 hours at $37^{\circ} \mathrm{C}$ in a shaking incubator $(100 \mathrm{rpm})$. The aerobic broth cultures contained approximately $5.0 \times 10^{8} \mathrm{CFU} / \mathrm{mL}$. The selection of mutants following transduction was performed on 
Luria Bertani agar (Lennox L 22700-025 Invitrogen) supplemented with nalidixic acid $(25 \mu \mathrm{g} / \mathrm{mL})$, kanamycin (30 $\mu \mathrm{g} / \mathrm{mL})$, or spectynomicin $(50 \mu \mathrm{g} / \mathrm{mL})$. Cultures for the detection of the $\mathrm{B}_{12}$ that was produced by the $S$. Enteritidis and $S$. Typhimurium strains were prepared in $10 \mathrm{~mL}$ of $\mathrm{M} 9$ glucose minimal medium supplemented with $\mathrm{CoC}_{2} \cdot 6 \mathrm{H}_{2} \mathrm{O}(1.2 \mathrm{mg} / \mathrm{L})$ and covered with a layer of Vaseline. To detect $B_{12}$ that was produced by the $S$. Gallinarum and $S$. Pullorum strains, the M9 minimal medium was supplemented with vitamin-free casaminoacid $(2 \%)$ and vitamin $\mathrm{B}_{1}$. This medium was then boiled to eliminate any remaining oxygen. Anaerobic cultures were incubated at $37^{\circ} \mathrm{C}$ for 24 hours.

Table 1. Salmonella strains used in this study.

\begin{tabular}{|c|c|c|}
\hline Strain & Relevant characteristics & Reference or source \\
\hline S. Gallinarum $9 \mathrm{Nal}^{\mathrm{r}}$ & Isolate from laying hens with Fowl Typhoid & IAH, Compton, UK \\
\hline S. Gallinarum $9 \mathrm{Nal}^{\mathrm{r}} \Delta \operatorname{cobS} \Delta c b i A$ & $\begin{array}{l}\text { Isogenic } c o b \mathrm{~S} \text { and } c b i \mathrm{~A} \text { deletion mutant of } S \text {. Gallinarum } \\
9 \mathrm{Nal}^{\mathrm{r}} \mathrm{Spec}^{\mathrm{r}} \mathrm{Kan}^{\mathrm{r}}\end{array}$ & 30 \\
\hline S. Enteritidis $\mathrm{Nal}^{\mathrm{r}}$ & Isolate from laying hens & IAH, Compton, UK \\
\hline$S$. Enteritidis $\mathrm{Nal}^{\mathrm{r}} \Delta \operatorname{cobS} \Delta c b i A$ & $\begin{array}{l}\text { Isogenic } c o b S \text { and } c b i \mathrm{~A} \text { deletion mutant of } S \text {. Enteritidis } \mathrm{Nal}^{\mathrm{r}} \\
\operatorname{Spec}^{\mathrm{r}} \operatorname{Kan}^{\mathrm{r}}\end{array}$ & This study \\
\hline S. Pullorum 449/87 Nal ${ }^{\mathrm{r}}$ & Isolate from laying hens with Pullorum disease & IAH, Compton, UK \\
\hline S. Pullorum 449/87 Nal ${ }^{\mathrm{r}} \Delta \operatorname{cob} S \Delta c b i A$ & $\begin{array}{l}\text { Isogenic cobS and cbiA deletion mutant of } S \text {. Pullorum 449/87 } \\
\mathrm{Nal}^{\mathrm{r}} \mathrm{Spec}^{\mathrm{r}} \mathrm{Kan}^{\mathrm{r}}\end{array}$ & This study \\
\hline S. Typhimurium F98 Nal ${ }^{\mathrm{r}}$ & Isolate from broiler chickens with Paratyphoid infection & IAH, Compton, UK \\
\hline S. Typhimurium F98 Nal ${ }^{\mathrm{r}}$ & Isogenic $\operatorname{cobS}$ and $c b i \mathrm{~A}$ deletion mutant of $S$. Typhimurium F98 & 41 \\
\hline$\Delta c o b S \Delta c b i A$ & $\mathrm{Nal}^{\mathrm{r}} \operatorname{Spec}^{\mathrm{r}} \mathrm{Kan}^{\mathrm{r}}$ & \\
\hline
\end{tabular}

$\mathrm{Nal}^{\mathrm{r}}$ nalidixic acid resistant; $\mathrm{Spec}^{\mathrm{r}}$ spetinomycin resistant; Kan ${ }^{\mathrm{r}}$ kanamycin resistant.

\section{Mutant construction}

Double $\Delta \operatorname{cobS} \Delta c b i A$ mutants for $S$. Enteritidis and $S$. Pullorum were constructed from single $S$. Gallinarum $\Delta c o b S S_{p e c}{ }^{\mathrm{r}}$ and $S$. Gallinarum $\Delta c b i A \operatorname{Kan}^{\mathrm{r}}$ mutants (30). Gene transference was carried out using the bacteriophage P22 followed by transduction according to standard protocols (37).

\section{Birds}

Virulence was assessed by oral inoculation of one-day-old Hy-line $₫$ commercial layers with $0.1 \mathrm{~mL}$ of culture containing $10^{8} \mathrm{CFU} / \mathrm{mL}$ of double mutant or wild type strains. We used the variety of Hy-line® Isa Brown layers for experiments conducted with Salmonella Pullorum and both Hy-line ${ }^{\circledR}$ varieties W36 and Isa Brown for the Salmonella Enteritidis assays. These birds were chosen because they are susceptible to Pullorum diseases and to Salmonella Enteritidis infection (3, 4, 13).

\section{Virulence assays}

Experiment 1. Assessment of mortality: This experiment was performed only with $S$. Pullorum because the adopted $S$. Enteritidis strain does not cause mortality (4). Each group contained 20 birds, and mortality was recorded over a period of 28 days. Data were assessed using the Chi-square test $(\mathrm{p}<0.05)$.

Experiment 2. Fecal excretion: This assay was performed only with Salmonella Enteritidis because this serovar extensively colonizes the gastrointestinal tract. The 
assay was carried out as previously described with some modifications (1). The challenge was performed as described in Experiment 1. Cloacal swabs were placed in selenite broth (CM0395 and LP0121A; Oxoid) containing $40 \mathrm{mg} / \mathrm{mL}$ of novobiocin (SN/ Nov) and were directly plated onto Brilliant Green Agar (BGA) (CM0263; Oxoid) containing 100 mg/mL of nalidixic acid and $0.04 \%$ novobiocin (BGA Nal/Nov). The cultures were incubated at $37^{\circ} \mathrm{C}$ for 24 hours. In the absence of growth, the appropriate enriched swab culture was streaked out onto fresh plates of BGA Nal/Nov.

Experiment 3. Assessment of systemic infection: The bacteriological analysis was performed as previously described with some modifications (1). At 2, 5, 7, 14, 21, and 28 days post-inoculation (dpi), samples from the spleen, liver, and cecal content were collected and diluted (1:10) in phosphate-buffered saline, $\mathrm{pH} 7.4$ (PBS). The organ samples were macerated using a mortar and pestle, and the cecal content was homogenized. A viable count for the number of mutant and wild type strains in the samples was estimated by plating aliquots of decimal dilutions onto BGA Nal/Nov and then incubating the cultures overnight at $37^{\circ} \mathrm{C}$. In the absence of growth on the BGANal/Nov, an equal volume of double-concentrated SN/Nov was added to the first dilution of the samples that was incubated at $37^{\circ} \mathrm{C}$ overnight and plated on BGANal/Nov. The plates were incubated at $37^{\circ} \mathrm{C}$ overnight. Data for the viable counts were transformed logarithmically $\left(\log _{10}\right)$, and their variance was analyzed (ANOVA). For media comparison Tuckey's test was used $(\mathrm{p}<0.05)$.

\section{Vitamin $B_{12}$. Detection and quantification}

Experiment 1. B B $_{12}$ MacConkey indicator medium: Anaerobic M9 cultures were plated on MacConkey indicator plates. MacConkey agar base supplemented with 1\% 1,2Propanediol (1,2-Pd) and $1 \mathrm{mg} / \mathrm{L} \mathrm{CoCl}_{2} \cdot 6 \mathrm{H}_{2} \mathrm{O}$ uses bile salts and the $\mathrm{pH}$ indicator neutral red to differentiate between strains that are capable of degrading 1,2-Pd to propionate. The bile salts are precipitated when propionic acid is produced, and this phenomenon is followed by the absorption of the neutral red indicator, imparting red color to the colonies. Strains that cannot degrade 1,2-Pd into propionic acid remain uncolored, and these strains were scored as white. Plates were incubated at $37^{\circ} \mathrm{C}$ for 24 hours.

\section{Experiment 2. Automated immunoassay for cobalamin} production: The automated immunoassay Immulite 1000 (Siemens®) was used to quantify vitamin $\mathrm{B}_{12}$. Salmonella strains were inoculated into M9 minimal medium containing Vaseline and were cultivated three times in the same medium. Cells grown in $50 \mathrm{~mL}$ of defined medium and incubated at $37^{\circ} \mathrm{C}$ for 24 hours were centrifuged at $4000 \mathrm{rpm}$ for 20 minutes. The pellets were washed twice with $0.2 \mathrm{M}$ potassium phosphate buffer ( $\mathrm{pH} 5.5)$ and then resuspended in the same buffer containing $0.1 \% \mathrm{KCN}$. The suspension was autoclaved for 15 minutes at $121^{\circ} \mathrm{C}$. The supernatant, which contained the extracted vitamin $B_{12}$, was filtered through a $0.2-\mu \mathrm{m}$ Millipore filter (33).

\section{RESULTS}

\section{Virulence assays}

Experiment 1. Mortality rates: No difference was observed between mortality rates for birds that were challenged with $S$. Pullorum $\Delta \operatorname{cobS} \Delta c b i A$ and $S$. Pullorum $\mathrm{Nal}^{\mathrm{r}}$ ( $\mathrm{p}>0.05$; data not showed).

Experiment 2. Fecal excretion: Figure 1 shows the number of $S$. Enteritidis-positive cloacal swabs. Intestinal colonization by the $S$. Enteritidis $\Delta \operatorname{cobS} \Delta \operatorname{cbiA}$ strains was increased in both Hy-line $\AA$ varieties W36 and Isa Brown layers compared to the $S$. Enteritidis $\mathrm{Nal}^{\mathrm{r}}$ strain $(\mathrm{p}<0.05)$.

Experiment 3. Assessment of systemic infection: No difference was observed between viable counts of $S$. Enteritidis $\Delta \operatorname{cobS} \Delta c b i A$ and $S$. Enteritidis $\mathrm{Nal}^{\mathrm{r}}$ in the livers and spleens of the two varieties Hy-line ${ }^{\circledR}$ W36 and Isa Brown that were used in this experiment $(\mathrm{p}>0.05)$. Similar to the data obtained for fecal excretion, higher counts of $S$. Enteritidis $\Delta c o b S \Delta c b i A$, as 
compared to $S$. Enteritidis $\mathrm{Nal}^{\mathrm{r}}$, were observed in the cecal contents of both varieties of layers that were analyzed. However, at 5 and $14 \mathrm{dpi}$, a difference was detected in the brown variety of the layer $(\mathrm{p}>0.05)$ (Figure 2$)$.
Figure 3 shows the results obtained for infection with $S$. Pullorum. Similar counts of $S$. Pullorum $\Delta \operatorname{cobS} \Delta c b i A$ and $S$. Pullorum $\mathrm{Nal}^{\mathrm{r}}$ were observed in the liver, spleen, and cecal contents $(p>0.05)$.

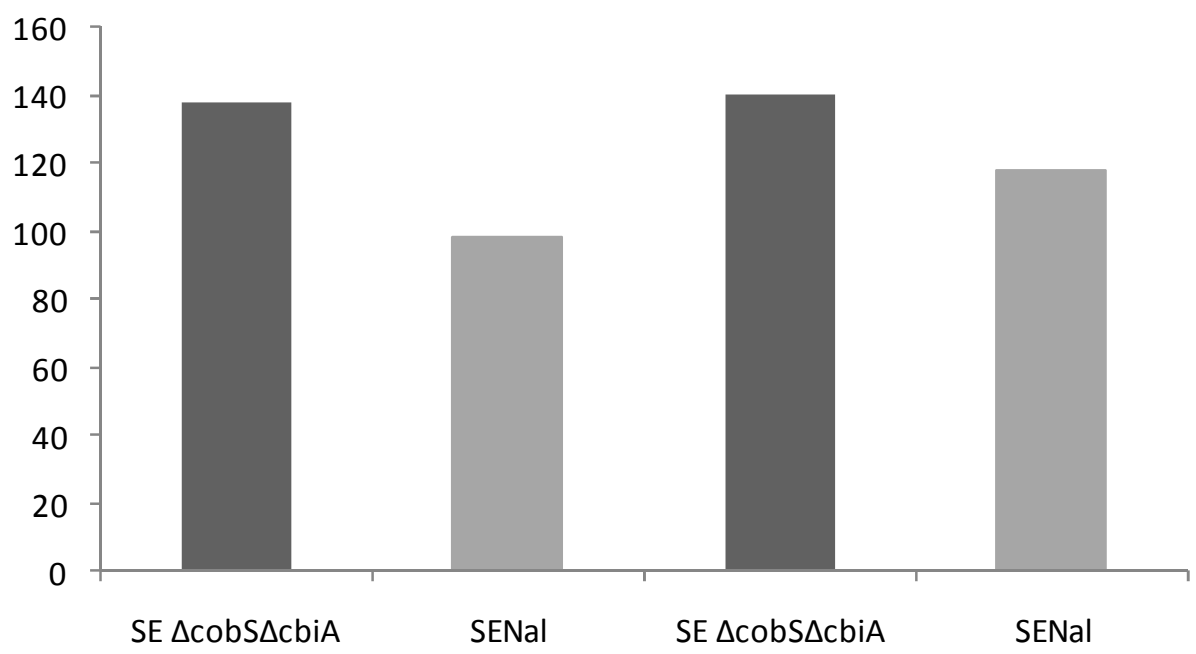

Figure 1. Recovery of Salmonella Enteritidis from cloacal samples from experimentally infected one-day-old white commercial layers and brown commercial layers; $*$ and $* *$ statistically significant $\left(\chi^{2} \mathrm{p}<0.05\right)$.
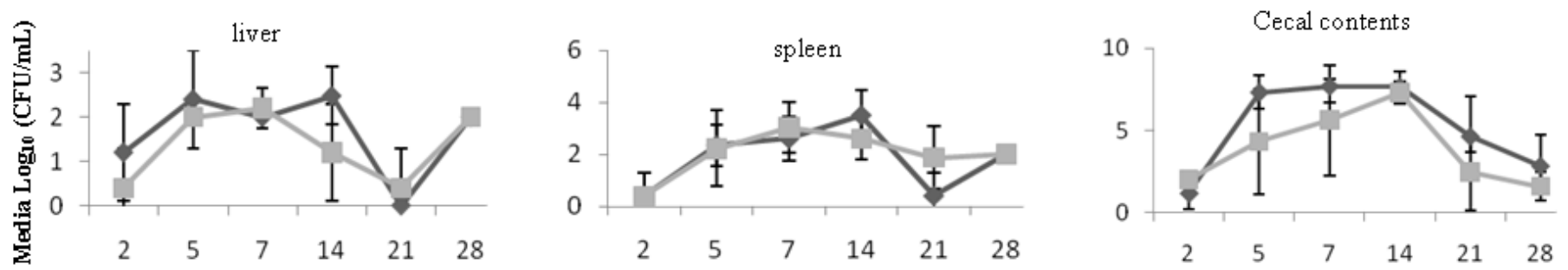

Days post infection of white variety layers

S. Enteritidis $\triangle c o b S \Delta c b i A$

S. Enteritidis $\mathrm{NaF}$
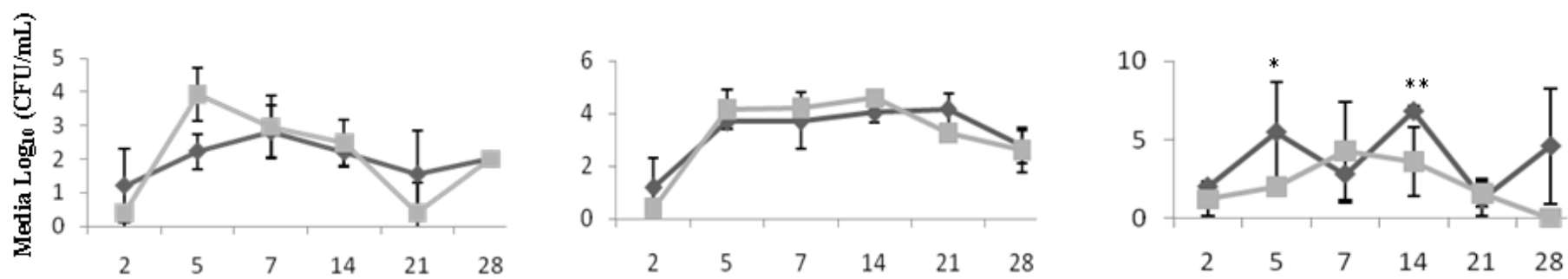

Days post infection of brown variety layers

Figure 2. Media of viable number $\left(\log _{10} \mathrm{CFU} / \mathrm{mL}\right)$ of Salmonella Enteritidis $\Delta \operatorname{cobS} \Delta c b i A$ and $S$. Enteritidis Nal ${ }^{\mathrm{r}}$ in liver, spleen, and cecal contents of birds experimentally infected at one day of age; $*$ and $* *$ statistically significant (Tuckey's test $(\mathrm{p}<0.05)$. 


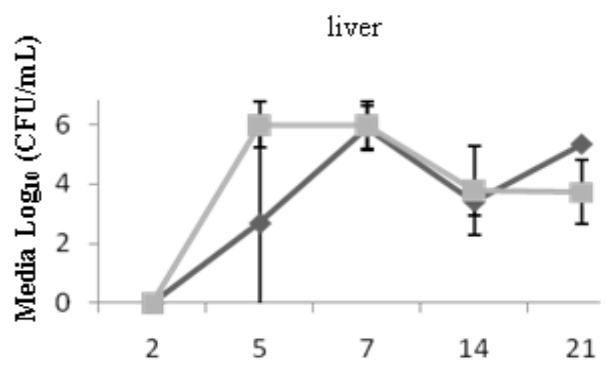

spleen

Cecal contents

Days post infection of brown variety layers

S. Pullorum $\triangle c o b$ S $\triangle$ cbiA
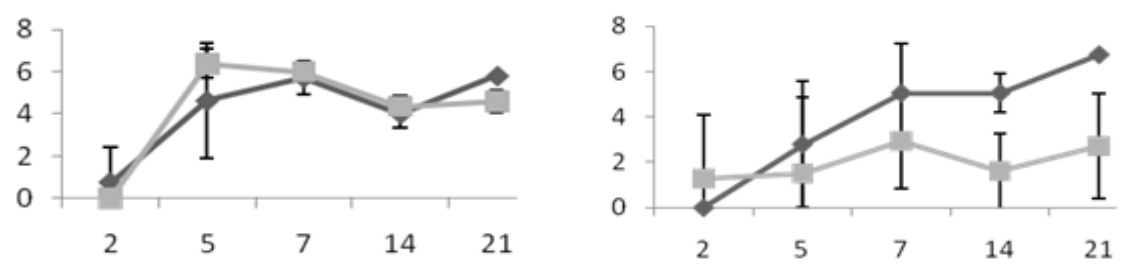

Figure 3. Media of viable number (Log10 CFU/mL) of Salmonella Pullorum $\Delta$ cobS $\Delta c b i A$ and $S$. Pullorum Nal ${ }^{\mathrm{r}}$ in liver, spleen, and cecal contents of brown commercial layers experimentally infected at one day of age. In the group infected with $S$. Pullorum Nal ${ }^{\mathrm{r}}$, the remaining birds died before 28 days post infection.

Vitamin $\mathbf{B}_{12}$. Detection and quantification: $S$. Pullorum $\Delta \operatorname{cobS} \Delta c b i A, S$. Enteritidis $\Delta \operatorname{cobS} \Delta c b i A$, and $S$. Typhimurium $\Delta \operatorname{cobS} \Delta c b i A$ strains do not synthesize cobalamin because the double mutation abrogates the cobalamin synthetic pathway. These strains produced uncolored colonies on MacConkey agar due to their inability to degrade propanediol without cobalamin, and their $B_{12}$ levels were below the inferior limit of detection in the Immulite assay. $S$. Pullorum $\mathrm{Nal}^{\mathrm{r}}, S$. Enteritidis $\mathrm{Nal}^{\mathrm{r}}$ and $S$. Typhimurium $\mathrm{Nal}^{\mathrm{r}}$ were positive for cobalamin production in both the MacConkey agar and the Immulite assays (Table 2). $S$. Gallinarum $\Delta \operatorname{cobS} \Delta \operatorname{cbiA}$ and $S$. Gallinarum $\mathrm{Nal}^{\mathrm{r}}$ did not synthesize cobalamin in either of the in vitro tests (Table 2).

Table 2. Production of cobalamin by Salmonella strains.

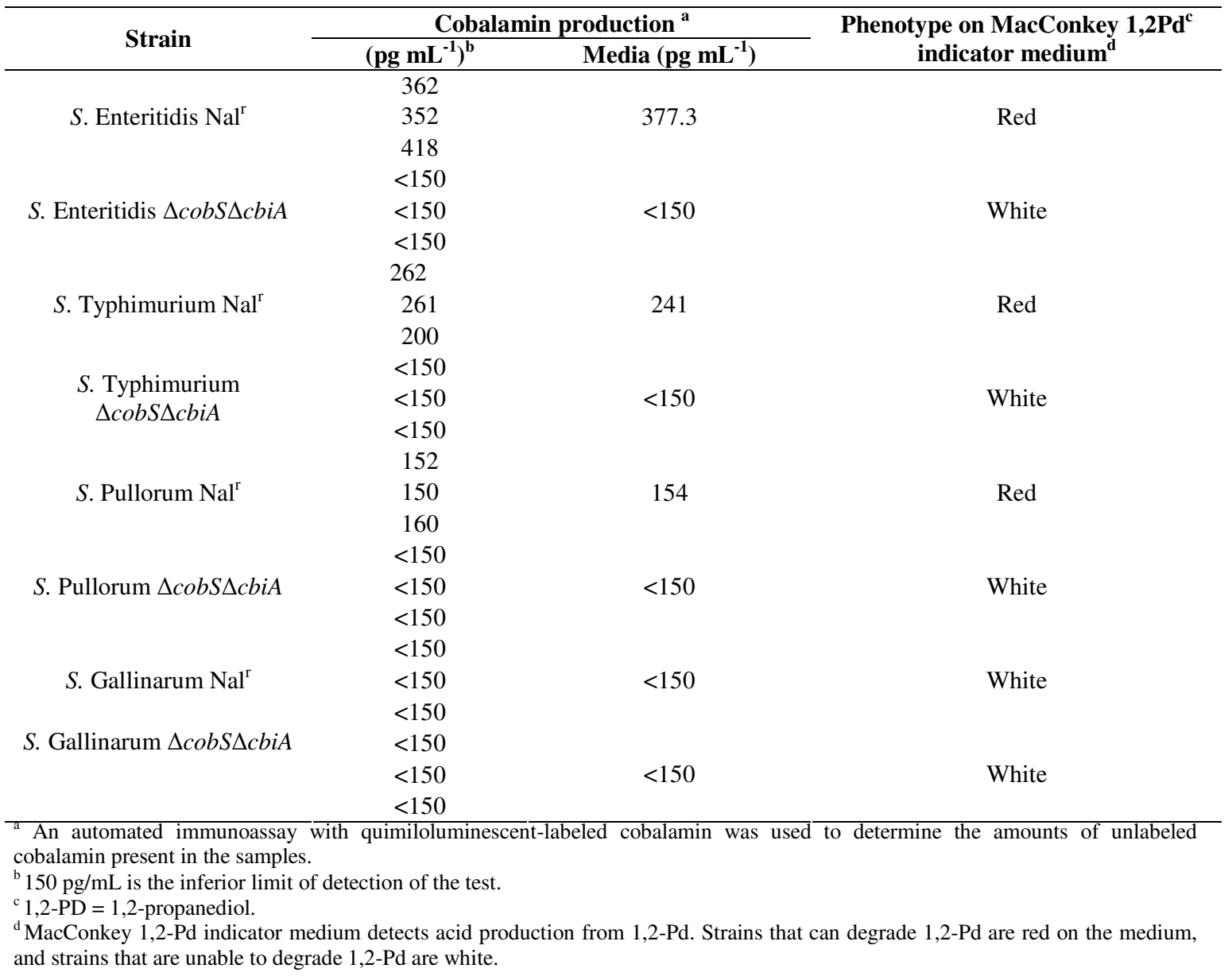




\section{DISCUSSION}

The cobalamin biosynthetic genes have been characterized in Salmonella Typhimurium. Most genes are located in a large 20-gene cluster 17 genes in cbi $A-P$, and 3 genes cob UST. Within this cluster, genes that encode the enzymes that are required for the three parts of the cobalamin synthesis pathway are grouped together. Mutations in these genes confer three phenotypes: $\mathrm{CobI}^{-}$(cbi genes), CobIII' (cobU and cobS genes) and $\mathrm{CobII}^{-}$(cobT gene) $(19,11)$. CobIII ${ }^{-}$mutants are unable to synthesize cobalamin, even if all of the precursor substrates are provided. In $S$. Typhimurium, the CbiA enzyme catalyzes the first step of adenosylcobnamide synthesis, and the CobS enzyme catalyzes the last step of adenosylcobnamide synthesis $(14,27)$. Thus, Salmonella $\Delta \operatorname{cobS} \Delta$ cbiA strains are unable to synthesize cobalamin. This phenotype was verified in our analysis of $\mathrm{B}_{12}$ production using either the MacConkey 1,2-Pd agar or the Immulite assays.

Salmonella Typhimurium synthesizes cobalamin de novo under anaerobic conditions (20). Many researchers have suggested that all isolates of Salmonella possess this ability $(36,32)$. Using two applied assays, we have demonstrated in the present study that Salmonella Gallinarum does not synthesize cobalamin under in vitro anaerobic conditions. However, $S$. Gallinarum appears to require this cofactor during infection in chickens. S. Gallinarum $\Delta c o b S \Delta c b i A$ caused no mortality, but the wild type strain killed $80 \%$ of the chickens (30). Therefore, induction of the $c o b$ operon seems to be active only during in vivo conditions, such as during an infection. Alternatively, $c o b$ genes are never induced, but their products directly target virulence genes. This hypothesis is supported by genome sequencing data for Salmonella Gallinarum 287/91, demonstrating a loss of function of genes that are related to cobalamin biosynthesis (pocR, cobD, cbiD, cbiC, cbiO,) and propanediol utilization by Salmonella Gallinarum ( $p d u G$ and $p d u O)$ as well as, independently, by $S$. Typhi (42).

The known cobalamin-dependent reactions in $S$. Typhimurium do not clearly justify this organism's large genetic investment in cobalamin biosynthesis and transport. The enzyme methionine synthetase is redundant, and the enzyme queosine synthetase is apparently nonessential. Propanediol utilization appears to be the primary use for cobalamin in S. Typhimurium (18). Propanediol is a useful and readily available carbon and energy source in the gastrointestinal tract of birds and mammals; because it is produced during the anaerobic catabolism of two common pentose sugars, rhamnose and fucose, and it is found in glycoconjugates present in the intestinal epithelium (29). In the presence of oxygen, propanediol serves as the sole carbon and energy source, but cobalamin is synthesized de novo under anaerobic growth conditions (18). Tetrationate is able to act as an alternative electrons acceptor, and its availability for $S$. Typhimurium in the host was demonstrated, recently (46). Tetrationate is product of gut inflammation, trigger by Salmonella, and the luminal sulphur compounds, the ability to use this new electron acceptor produce a growth advantage for $S$. Typhimurium over the competing luminal microbiota (46). Also, the ability to degrade 1,2-Pd confers a selective advantage in anaerobic niches, such as the intestinal tract of host animals, and within macrophages (26, 29). Evidence suggests that 1,2-Pd plays a role in Salmonella pathogenesis. In vivo expression technology (IVET) indicates that $1,2-\mathrm{Pd}$ degradation is important for S. Typhimurium growth in host tissues, and competitive index studies in mice indicate that $p d u$ but not cob confers a virulence defect in $S$. Typhimurium (9, 16). The $p d u$ locus is positioned adjacent to the $c o b$ operon, and both operons are controlled globally by the same systems in both aerobic and anaerobic conditions. Furthermore, both operons are induced by propanediol $(5,9)$. Deficiencies in invasion by $c o b-c b i-p d u$ cluster-mutated $S$. Typhimurium have been observed in mice, demonstrating that the cob-cbi-pdu gene cluster increases the intracellular fitness of Salmonella (23). The $\Delta \operatorname{cobS} \triangle c b i A$ deletion in $S$. Typhimurium partially reduces the pathogenicity of the bacteria in broiler chickens $(41)$

As previously observed for $S$. Typhimurium that contain 
defective genes related to vitamin $\mathrm{B}_{12}$ biosynthesis $(38,5)$, the $\Delta \operatorname{cobS} \Delta c b i A \quad S$. Enteritidis and $\Delta \operatorname{cobS} \Delta c b i A \quad S$. Pullorum mutants exhibited normal growth under both aerobic and anaerobic conditions. Both $S$. Enteritidis and $S$. Pullorum maintained the ability to colonize the avian intestinal tract and cause systemic infection. In addition, fecal excretion and cecal colonization by $S$. Enteritidis $\Delta c o b S \Delta c b i A$ was higher than that induced by the wild type $S$. Enteritidis strain $(\mathrm{p}<0.05)$. $S$. Pullorum and $S$. Gallinarum are avian host-specific pathogens, whereas $S$. Enteritidis has a broad range of hosts. Although these three serovars belong to the same monophyletic group, they differ in their pathogenicity characteristics (25). The primary importance of cobalamin biosynthesis for these three serovars remains unclear and might be variable. The survival of $S$. Enteritidis in chickens does not appear to require cobalamin. Although they are responsible for causing distinct diseases, $S$. Pullorum and $S$. Gallinarum have been historically considered to be very similar based on their relationship with birds and their phenotypic behavior. They are also easily distinguished from $S$. Enteritidis (2). However, in terms of vitamin $\mathrm{B}_{12}$ requirement, $S$. Enteritidis and $S$. Pullorum appear to be more similar to each other and to differ from $S$. Gallinarum. The identification of the genetic and environmental factors that regulate specific in vivo-induced (ivi) genes expression, as well as the host site(s) in which these genes are expressed, can provide clues about the intracellular environment and possible functions for $i v i$ genes in these specific host tissues. The functions of some of these genes might change depending on the context of the animal, organ, cell type, or sub-cellular compartment that the organism inhabits. In the present study, such clues proved to be useful for understanding S. Gallinarum but not the other Salmonella serotypes (16). Signals present specifically in pig tonsils induce the $c o b$ operon of $S$. Typhimurium, either as a requirement for survival in the tonsil or as a prelude to migration into the intestinal tract (17).

Several comparative studies between $S$. Gallinarum and other Salmonella serotypes have demonstrated differences in the cellular mechanisms that might be responsible for the specificity and adaptability of $S$. Gallinarum to the avian host $(43,45,22,44,8)$. For example, glycogen has a complex role in survival and, therefore, in prolonging the infectivity of broad-host-range Salmonella outside of the host. It also plays a minor role in Salmonella virulence and colonization (28). S. Gallinarum and $S$. Pullorum do not accumulate glycogen under test conditions (21). The loss of glycogen synthesis is an example of pseudogene accumulation by host-restricted serovars and is indicative of functions that are no longer required due to niche specialization. Host adaptation is often associated with extensive gene deletion (7) and complex nutritional requirements, as observed in other host-adapted serovars, such as $S$. Typhi.

Salmonella enterica is a bacterial species that includes examples of both promiscuous and host-adapted pathotypes. There is a consensus among researchers that the selection pressure to maintain $\mathrm{B}_{12}$ synthesis varies with the lifestyle of the organism. Escherichia coli does not maintain a complete cob operon and seems to fill a niche that does not require complete de novo cobalamin synthesis. Conversely, the ability of $S$. Enteritidis and $S$. Typhimurium to synthesize $\mathrm{B}_{12}$ must be strongly selected for as these organisms maintain the full operon. If we identify the precise moment at which the $c o b$ operon is induced (if at all) in $S$. Enteritidis, $S$. Typhimurium, $S$. Gallinarum, and $S$. Pullorum, we might develop a better understanding of its importance for colonization, multiplication, survival in macrophages, and immune evasion.

\section{ACKNOWLEDGEMENTS}

This work was supported by Fapesp.

We thank Dr. James Warren and Dr. Evelyne Raux Deery from the University of Kent, UK, both for the donation of MacConkey agar for $\mathrm{B}_{12}$ detection and for technical support.

We also thank Dr. Fernando Sesma from Tucuman, Argentina for his dedication and patience while he taught us. 


\section{REFERENCES}

1. Barrow, P.A.; Lovell, M.A. (1991). Experimental infection of egg-laying hens with Salmonella enteritidis phage type 4. Avian Pathol. 20 (2), 335348.

2. Berchieri Jr. A.; Freitas Neto, O.C. (2009). Salmoneloses aviárias. p.435451. In: Berchieri Jr. A., Silva, E.N., Fabio, J., Sesti, L., Zuanaze, M.A.F. (eds). Doença das aves. $2^{\text {nd }}$. Facta, Campinas, Brazil, p. 128-158.

3. Berchieri Jr, A.; Murphy, C.K.; Marston, K.; Barrow, P.A. (2001). Observations on the persistence and vertical transmission of Salmonella enterica serovars Pullorum and Gallinarum in chickens: effect of bacterial and host genetic background. Avian Pathol. 30 (1), 221-231.

4. Berchieri Jr, A.; Wigley, P.; Page, K.; Murphy, C.K.; Barrow, P.A. (2001). Further studies on vertical transmission and persistence of Salmonella enterica serovar Enteritidis phage type 4 in chicken. Avian Pathol. 30, 297-310.

5. Björkman, J.; Rhen, M.; Anderson, D.I. (1996). Salmonella Typhimurium $c o b$ mutants are nor hyper-virulent. FEMS Microbiol. Lett. $139,121-126$

6. Bobik, T.A.; Xu, Y.; Jeter, R.M.; Otto, K.E.; Roth, J.R. (1997). Propanediol utilization genes $(p d u)$ of Salmonella typhimurium: three genes for the propanediol dehydratase. J. Bacteriol. 179, 6633-6639.

7. Boyd, E.F.; Porwollik, S.; Blackmer, F.; McClelland, M. (2003). Differences in gene content among Salmonella enterica serovar Typhi isolates. J. Clin. Microbiol. 41, 3823-3828.

8. Chadfield, M.S.; Brown, D.J.; Aabo, S.; Christensen, J.P; Olsen, J.E. (2003). Comparison of intestinal invasion and macrophage response of Salmonella Gallinarum and other host-adapted Salmonella enterica serovars in the avian host. Vet. Microbiol. 92, 49-64

9. Conner, C.P.; Heithoff, D.M.; Julio, S.M.; Sinsheimer, R.L.; Mahan, M.J. (1998). Differential patterns of acquired virulence genes distinguish Salmonella strains. Proc. Natl. Acad. Sci. USA. 95, 4641-4645.

10. Dunlap, N.E.; Benjamin W.H.; McGall Jr, R.D; Tilden, A.B.; Briles, D.E. (1991). A "safe-site" for Salmonella typhimurium is within splenic cells during the early phase of infection in mice. Microbial Pathog. 10, 297-310.

11. Escalante-Semerena, J.C.; Johnson, M.G; Roth, J.R. (1992). The CobII and CobIII regions of the cobalamin (vitamin $\mathrm{B}_{12}$ ) biosynthetic operon of Salmonella typhimurium. J. Bacteriol. 174, 24-29

12. Eschenmoser A. (1988). Vitamin $B_{12}$ : experiments concerning the origin of its molecular structure. Angew. Chem. Int. Ed. Engl. 27, 5-39.

13. Freitas Neto, O.C.; Mesquita, A.L; Paiva, J.B; Zotesso, F.; Berchieri Jr, A. (2008). Control of Salmonella enterica serovar Enteritidis in laying hens by inactivated Salmonella Enteritidis vaccine. Braz. J. Microbiol. 39, 390-396.

14. Fresquet, V.; Willians, L.; Raushel, M. (2004). Mechanism of cobyrinic acid a,c-diamide synthetase from Salmonella typhimurium LT2.
Biochem. 43, 10619-10627.

15. Frey, B.; McCloskey, J.; Kersten, W.; Kersten, H. (1988). New function of vitamin $\mathrm{B}_{12}$ : cobamide-dependent reduction of epoxyqueosine to queosine in tRNAs of Escherichia coli and Salmonella typhimurium. $J$ Bacteriol. 170, 2078-2082.

16. Heithoff, D.M.; Conner, C.P; Hentschel, U.; Govantes, F.; Hanna, P.C.; Mahan, M.J. (1999). Coordinate Intracellular Experssion of Salmonella Genes Induced during Infection. J. Bacteriol. 181, 799-807.

17. Huang, Y.; Leming, C.L.; Suyemoto, M.; Altier, C. (2007). Genomewide screen of Salmonella genes expressed during infection in pigs, using in vivo expression technology. Appl. Environ. Microbiol. 73, 75227530 .

18. Jeter, R. M. (1990). Cobalamin-dependent 1,2 propanediol utilization by Salmonella typhimurium. J. Gen. Microbiol. 136, 887-896.

19. Jeter, R.M.; Roth, J.R. (1987). Cobalamin (vitamin B $_{12}$ ) biosynthetic genes of Salmonella typhimurium. J. Bacteriol.169, 3189-98.

20. Jeter, R.M; Oliveira, B.M; Roth, J.R. (1984). Salmonella typhimurium synthesizes cobalamin (vitamin $\mathrm{B}_{12}$ ) de novo under anaerobic growth conditions. J. Bacteriol. 159, 206-216.

21. Jin, X.; Ballicora, M.A; Preiss, J.; Geiger, J.H. (2005). Crystal structure of potato tuber ADP-glucose pyrophosphorylase. EMBO J. 24, 694-704.

22. Kaiser, P.; Rothwell, L.; Galyov, E.E.; Barrow, P.A.; Burnside, J.; Wigley, P. (2000). Differencial cytokine expression in avian cells in response to invasion by Salmonella typhimurium, Salmonella enteritidis and Salmonella gallinarum. Microbiol. 146, 3217-3226.

23. Klumpp, J.; Fuchs, T.M. (2007). Identification of novel genes is genomic islands that contribute to Salmonella typhimurium replication in macrophages. Microbiol. 153, 1207-1220.

24. Lawrence, J.G.; Roth, J.R. (1995). The cobalamin (coenzyme B 12 ) biosynthetic genes of Escherichia coli. J Bacteriol. 177, 6371-6380.

25. Li, J.; Smith, N.H.; Nelson, K.; Crichton, P.B.; Old, D.C.; Whittam, T.S.; Selander, R.K. (1993). Evolutionary origin and radiation of the avianadapted non-motile salmonellae. J. Med. Microbiol. 38, 129-139.

26. Lin, E.C.C. (1987). Dissimilatory pathways for sugars, polyols, and carboxy-lates. In Neidhardt, F.D., Ingraham, J.L., Low, K.B., Magasanik, B., Schaechter, B., Umbarger, H.E. (eds). Escherichia coli and Salmonella Typhimurium: cellular and molecular biology. ASM, Press, Washington DC, USA, p. 244-284

27. Maggio-Hall, L.A.; Claas, J.R.; Escalante-Semerena, J.C. (2004). The last step in coenzyme $\mathrm{B}_{12}$ synthesis is localized to the cell membrane in bacteria and archaea. Microbiol. 150, 1385-1395.

28. McMeechan, A.; Lovell, M.A.; Cogan, T.A.; Marston, K.L; Humprey, T.J.; Barrow, P.A. (2005). Glycogen production by different Salmonella enterica serotypes: contribution of functional $g \operatorname{lgC}$ to virulence, intestinal colonization and environmental survival. Microbiol. 151, 39693977.

29. Obradors, N.; Badıa, J.; Baldoma, L.; Aguilar, J. (1988). Anaerobic 
metabolism of the L-rhamnose fermentation product 1,2-propanediol in Salmonella typhimurium. J. Bacteriol. 170, 2159-62.

30. Paiva, J.B.; Penha Filho, R.A.C.; Sierra, Y.M.A.; Berchieri Jr, A., Lemos, M.V.F.; Barrow, P.A. (2009). A defective mutant of Salmonella enterica serovar Gallinarum in cobalamin biosynthesis is avirulent in chickens. Braz. J. Microbiol. 40, 495-504.

31. Pejchal, R.; Ludwig, M.L. (2005). Cobalamin-Independent Methionine Synthase (MetE): A Face-to-Face Double Barrel That Evolved by Gene Duplication. Plos. Biol. 3, e31.

32. Price-Carter, M.; Tingey, J.; Bobik, T.A.; Roth, J.R. (2001). The alternative electron acceptor tetrathionate supports B12-dependent anaerobic growth of Salmonella enterica serovar Typhimurium on ethanolamine or 1,2-propanediol. J. Bacteriol. 183, 2463-2475.

33. Riaz, M.; Ansari, Z.A.; Iqbal, F.; Akram, M. (2007). Microbial production of vitamin B12 by methanol utilizing strain of Pseudomonas specie. Pak. Biochem. Mol. Biol. 40, 5-10.

34. Roof, D.M.; Roth, J.R. (1988). Ethanolamine utilization in Salmonella typhimurium. J. Bacteriol. 170, 3855-3863.

35. Roof, D.M.; Roth, J.R. (1989). Functions required for vitamin-B12 dependent ethanolamine utilization in Salmonella typhimurium. J. Bacteriol. 171, 3316-23.

36. Roth, J.R.; Lawrence, J.G.; Bobik, T.A. (1996). Cobalamin (coenzyme $\mathrm{B}_{12}$ ): synthesis and biological significance. Annu. Rev. Microbiol. 50, 137-181.

37. Sambrook, J.; Russel, D.W. (2001). Molecular cloning. A laboratory manual. Ed. Cold Spring Harbor Laboratory Press.

38. Sampson, B.A.; Gotschlich, E.C. (1992). Elimination of the Vitamin B B $_{12}$ uptake or synthesis pathway does not diminish the virulence of Escherichia coli $\mathrm{K} 1$ or Salmonella typhimurium in Three Model Systems. Infect. Immun. 60, 3518-3522.

39. Scott AI. (1990). Mechanistic and evolutionary aspects of vitamin B12 biosynthesis. Acc. Chem. Res. 23, 308-17.
40. Scott AI. (1993). How nature synthesizes vitamin B12 - a survey of the last four billion years. Angew. Chemie. 32, 1223-43.

41. Sierra, Y.M., Paiva, J.B.; Penha Filho, R.A.C.; Berchieri Jr. A. (2010). Participation of genes involved in the process of anaerobic respiration of infection in chickens by Salmonella Typhimurium. Braz. J. Vet. Pathol. 3 (1), 2-8.

42. Thomson, N.R.; Clayton, D.J.; Windhorst, D.; Vernikos, G.; Davidson, S.; Churcher, C.; Quail, M.A.; Stevens, M.; Jones, M.A.; Watson, M.; Barron, A.; Layton, A.; Pickard, D.; Kingsley, R.A.; Bignell, A.; Clark, L.; Harris, B.; Ormond, D.; Abdellah, Z.; Brooks, K.; Cherevach, I.; Chillingworth, T.; Woodward, J.; Norberczak, H.; Lord, A.; Arrowsmith, C.; Jagels, K.; Moule, S.; Mungall, K.; Sanders, M.; Whitehead, S.; Chabalgoity, J.A.; Maskell, D.; Humphrey, T.; Roberts, M.; Barrow, P.A.; Dougan, G.; Parkhill, J. (2008). Comparative genome analysis of Salmonella Enteritidis PT4 and Salmonella Gallinarum $287 / 91$ provides insights into evolutionary and host adaptation pathways. Genome Res. 18, 1624-1637.

43. Wallis, T.S.; Wood, M.; Watson, P.; Paulin, S.; Jones, M.; Galyov, E. (1999). Sips, Sops and SPIs but not stn influence Salmonella enteropathogenesis. Adv. Exp. Med. Biol. 473, 275-280.

44. Wigley, P.; Hulme, S.D.; Bumstead, N.; Barrow, P.A. (2002). In vitro and in vivo studies of genetic resistance to systemic salmonellosis in the chicken encoded by SAL1 locus. Microbes Infect. 4, 1111-1120.

45. Wilson, R.; Elthon, J.; Clegg, S.; Jones, B.D. (2000). Salmonella enterica serovars Gallinarum and Pullorum expressing Salmonella enterica serovar Typhimurium type I fimbriae exhibit increased invasiness for mammalian cells. Infect. Immun. 68, 4782-4785.

46. Winter, S.E.; Thiennimitr, P.; Winter, M.G.; Butler, B.P.; Huseby, D.L.; Crawford, R.W.; Russel, J.M.; Bevins, C.L.; Adams, G.; Tsolis, R.M.; Roth, J.R; Bäumler, A.J. (2010). Gut inflammation provides a respiratory electron acceptor for Salmonella. Nature. 467, 426-429. 